\title{
Prevention of mother to child transmission lay counsellors: Are they adequately trained?
}

\author{
Authors: \\ Catherine $\mathrm{H}$. Thurling ${ }^{1}$ \\ Candice Harris ${ }^{1}$ \\ Affiliations: \\ ${ }^{1}$ Department of Nursing, \\ University of the \\ Witwatersrand, South Africa \\ Correspondence to: \\ Catherine Thurling \\ Email: \\ hilary.thurling@wits.ac.za \\ Postal address: \\ 7 York Road, Parktown 2193, \\ South Africa \\ Dates: \\ Received: 26 Sep. 2011 \\ Accepted: 12 Mar. 2012 \\ Published: 5 June 2012 \\ How to cite this article: \\ Thurling, C.H. \& Harris, \\ C., 2012, 'Prevention of \\ mother to child transmission \\ lay counsellors: Are they \\ adequately trained?' \\ Curationis 35(1), Art. \#64, \\ 7 pages. http://dx.doi. \\ org/10.4102/curationis. \\ v35i1.64
}

C 2012. The Authors

Licensee: AOSIS

OpenJournals. This work

is licensed under the

Creative Commons

Attribution License.
South Africa's high prevalence of human immunodeficiency virus (HIV) infected women requires a comprehensive health care approach to pregnancy because of the added risk of their HIV status. As a result of the shortage of health care workers in South Africa, lay counsellors play important roles in the prevention of mother to child transmission of HIV (PMTCT).

There is no standardization of training of lay counsellors in South Africa, and training varies in length depending on the training organisation.

The study aimed to investigate the training of lay counsellors by analysing their training curricula and interviewing lay counsellors about their perceptions of their training.

A two phase research method was applied. Phase one documented an analysis of the training curricula. Phase two was semi-structured interviews with the participants. Purposive sampling was undertaken for this study. The total sample size was 13 people, with a final sample of 9 participants, determined at the point of data saturation.

The research was qualitative, descriptive and contextual in design. The curricula analysed had different styles of delivery, and the approaches to learning and courses varied, resulting in inconsistent training outcomes. A need for supervision and mentorship in the working environment was also noted.

The training of lay counsellors needs to be adapted to meet the extended roles that they are playing in PMTCT. The standardization of training programmes, and the incorporation of a system of mentorship in the work environment, would ensure that the lay counsellors are adequately prepared for their role in PMTCT.

\section{Introduction and Background}

The prevalence of (human immunodeficiency virus) (HIV) and AIDS in pregnant women has not followed the same pattern of stabilizing, as this occurred in the heterosexual population, which resulted from an improvement in access to HIV treatment. More than $29 \%$ of women who accessed public health services in South Africa in 2008 tested positive for HIV (Health Systems Trust 2010; USAID 2009). Many South African women only discover their HIV positive status after becoming pregnant and attending antenatal care, and as a result of this the supportive and educational roles of lay counsellors in the prevention of mother to child transmission of HIV (PMTCT) cannot be over estimated. PMTCT is defined as the prevention of the vertical transmission of the human immunodeficiency virus from an infected mother to her baby via the placenta during pregnancy, through blood contamination during childbirth, or breast feeding (Van Dyk 2008:42).

Health education provided by lay counsellors starts at the entry point of a pregnant woman into the PMTCT services. The process involves the mother first identifying her HIV status, then post test counselling is undertaken by the lay counsellors. The counsellors continue to provide information, education and communication with the mother, concerning her HIV status, until after the birth of the baby, and until her baby is approximately eighteen months old.

A community health worker is defined as 'any health worker carrying out functions related to health care delivery; trained in some way in the context of the intervention [to HIV and health care] and having no formal or processional certificate' (Daniels, Nor, Jackson, Ekström, Doherty 2010:2). Lay counsellors are found under the umbrella of community health workers, and their training varies in length depending on the training organisation. There is no standardization of lay counsellors' training, but literature indicates that most lay counsellors' programmes include training in the provision of health education, counselling of patients on treatment adherence and other HIV related issues. Some lay counselling programmes train counsellors to perform basic health workers' duties such as recording patients heights, weights and basic vital signs (Campbell and Scott 2009; Lehman and Sanders 2007; Morris et al. 2009). 
Lay health workers can take over the non clinical as well as some of the clinical tasks, in medical facilities, in order to free up the nurses. In Maseru, Lesotho, the results of a study on task shifting, found that some of the counsellors were weighing patients, preparing laboratory forms, filing and recording blood results as well as performing HIV rapid tests (Morris et al 2009). The results were that the health service was better utilized as more patients could be attended to, which resulted in more efficient service delivery.

As many South African women only discover their HIV status after becoming pregnant and attending antenatal care, the supportive and educational roles of lay counsellors in the prevention of mother to child transmission of HIV (PMTCT) cannot be over estimated. This scenario is compounded by the high prevalence of HIV in pregnant women, who then require a comprehensive health care approach to their pregnancy and HIV positive status.

In a resource limited country like South Africa where a shortage of health care workers exists, health volunteers are playing a greater role in the provision of HIV and AIDS services and support. 'Task shifting' is the name given to a process of delegating tasks from more specialized to less specialized health workers. By reorganizing the workforce in this way, task shifting can make more effective use of the human resources currently available. It requires the integration of the concept of new cadres and their roles in the system, it changes scopes of practice and regulatory frameworks, and it enhances training infrastructure into the main health system (World Health Organization 2007:3). Task shifting involves the extension of the role of lay counsellors, in order for them to assume tasks previously undertaken by senior cadres of health workers, such as nurses, midwives, non physician clinicians and medical doctors (WHO 2008:81).

\section{Problem Statement}

The response to the HIV and AIDS epidemic in South Africa has given rise to a large lay population of counsellors and educators, who have become integrated into the health system and within which they maintain a significant presence. Nurses have found themselves unable to cope with the HIV epidemic and, through task shifting, are handing over traditional nursing roles to lay counsellors and community health workers (Campbell and Scott 2009). Problems have arisen with the lay counsellors' 'Cinderella' status in the health sector, and the uneven training that they have received (Aids foundation 2009). The training that lay educators and counsellors receive is usually from non-governmental organizations (NGO) or faith based organizations (FBO). Consequently there is no standardization and minimum training requirements, which can result in Community health Workers (CHW) performing tasks in the clinical environment that they have not been adequately trained to perform.

\section{Aim of the study}

The aim of this study was to evaluate the current training of lay counsellors through an analysis of their current training curricula. Following this the research investigated the thoughts and feelings that the lay counsellors held about the training that they had undertaken and how it had prepared them to fulfil their roles in PMTCT.

\section{Research objectives}

The aim of the study was achieved through the following objectives:

- to explore and describe the training manuals and curricula that were studied in the training of lay HIV and AIDS counsellors and educators

- to explore and describe the perceptions of the lay counsellors and educators about the training that they undertook.

\section{Significance of the study}

In a resource limited country such as South Africa where a shortage of health care workers exists, health volunteers are playing a greater role in the provision of HIV and AIDS services and support. Lay counsellors appear to be the best provider of this bridge between formal health care and the community (Schneider, Hlope, Van Rensburg 2008:7). Task shifting involves the extension of the role of the lay counsellors, in order for them to assume tasks previously undertaken by senior cadres of health workers, such as nurses, midwives, non physician clinicians and medical doctors (WHO 2008:81).

An educationally based participant focused programme that is well thought out and designed, with specific goals and outcomes, would result in greater competence based on training, and would result in better outcomes for PMTCT programmes that include lay counsellors.

\section{Research method and design Design}

The research was qualitative, descriptive, and contextual in design. The objectives were to explore and describe the training curricula for PMTCT lay counselling, as well as what the lay counsellors identified as essential skills that should be included in future training curricula. The context of the study was the maternity section of an urban academic hospital where PMTCT is practiced by lay counsellors.

\section{Population}

The population is the entire group of persons involved in PMTCT lay counselling, which is of interest to the researcher (Nieswiadomy 2008:188). For this research the study population consisted of the total population of lay counsellors who provide PMTCT care at the large tertiary hospital selected $(N=13)$.

\section{Sampling}

The researcher purposively selected participants who provided maximum and relevant information on the issue being investigated (Henning 2004:71; Creswell 2009:178). 
The final sample was determined by the quality of the data collected, when no new data emerged from the interviews, data saturation had been reached. The final sample was reached with nine participants.

\section{Data collection method}

A two phase research method was applied for this study. Phase One was a document analysis of the training curricula studied by the participants, which the researcher sourced from the participants. This was to gain an understanding of the training curricula taught to them, prior to conducting interviews with the participants. This was in order to more accurately centre the interviews and establish the impact that the curricula had on their performance. Three training curricula were analysed, using a researcher formulated curriculum guide. These were analysed for:

- components of a formal curriculum

- principles of adult education

- learning outcomes

- the theory to practice ratio

- content

The last two points are of particular emphasis as adults learn effectively when they fully participate in the learning experience, and through the identification of their learning needs and objectives. PMTCT is implemented in the clinical areas and, therefore, it was deemed important to note the theory to practice ratio in the curricula.

Phase Two was semi-structured individual interviews with lay counsellors who had been working in the field of PMTCT for at least six months. The researcher used an interview guide to give direction to the interviews.

The trustworthiness of the data, obtained from the individual interviews, were achieved through triangulation and the introduction of a focus group. The focus group was intended to allow the participants to confirm, add or alter data to ensure accuracy of the data collected through the semistructured interviews. All the participants were invited to participate in the group, of which four participants joined the focus group, three members had been involved in the individual data collection interviews and one member was a new participant.

\section{Data analysis}

\section{Findings and discussion from the analysis of the training curricula}

Curriculum A was a generic ad hoc curriculum studied by health workers working with HIV and AIDS patients. It resulted in the lack of relevant and appropriate goals and learning outcomes that are specific to community health workers. This curriculum was also entirely classroom based with no follow up or mentoring of the student once they had completed the training.

Literature reviewed for this study suggests that curricula should be specifically developed for community health workers (Lehman and Sanders 2007). Curricula that are too classroom based were often found to be inadequate, but where training is implemented in an environment with hands on real life experience, the training is often more effective (Battarcharya, Winch, Le Ban, and Tien 2001). Assessment and evaluation is an integral part of a curriculum as it provides feedback about what learning has occurred in relation to the learning objectives. In this curriculum the learning objectives were not identified and, therefore, assessment could not be a planned evaluation of what was achieved by the learner (Meyer and van Niekerk, 2008).

Curriculum B was a curriculum designed for HIV and AIDS counsellors specifically, that required the counsellors to attended class everyday for two months. On completion of the curriculum, students were followed up and supervised in their clinical area for a limited period of time. Learning objectives were identified, and formative assessment of the learner was taken through reflective journaling and completing a written exercise. Summative assessment required a written paper containing both an essay and multiple choice questions.

The researcher noted, in her analysis of this curriculum, that in the introduction the students were asked to critically evaluate themselves during the course, as well as to establish an atmosphere of sharing and providing feedback amongst themselves. This enabled them to further understand the complexities of people living with HIV and AIDS. The learner thereby becomes actively involved in the learning process through reflection of their own experiences (Beard and Wilson, 2007). Role playing was implemented as a learning strategy, which is an appropriate method of teaching. This was enhanced with the provision of a checklist that the student could consult to guide her or his interaction with the patient, by identifying the critical points in the checklist.

Curriculum $\mathrm{C}$ was in the process of being accredited by the Health Workers Sector Education and Training Authority (HWSETA) and it, therefore, had a more formal structure than the other two curricula that were analysed for this study. This curriculum was run over a year with the learners attending training (theory) for one week per month and undergoing practical training in their work environment for three weeks. For the duration of the theoretical part of the curriculum the counsellors had the opportunity to interact with other counsellors who may have been working in a different health care facility. This allowed for the sharing of different experiences and a more diverse learning opportunity. Interaction between community health workers and learners plays a great motivational role as the CHWs feel part of a community, and each group can mutually reinforce the other's commitment to making a difference in health care (Battacharyya et al. 2001).

This curriculum had all the components of a formal curriculum, and learners who complete this course would have a qualification, once the accreditation process 
was completed, that would allow them to progress on a career path.

All three curricula that were analysed are in line with the literature reviewed for this study. They all had very different styles of delivery, their duration varied as well as their theory practice content, which resulted in a varied exit level for lay counsellors.

\section{Data analysis of semi-structured interviews}

The second objective was to explore the thoughts and feelings that the counsellors had regarding their training. Nine participants were interviewed, the youngest being 25 years old and the oldest being 45 years old. Four of the counsellors had a matriculation certificate and the remaining five had Grade 11. Eight of the participants had received additional PMTCT training, one participant had not received additional training, but PMTCT had been included in her basic counselling training.

Open coding was applied as a method of making sense out of the data (Bailey 2007). Five themes and five sub themes emerged from the data collected, and are discussed below, with the actual participants quotes written in italics.

\section{Theme 1: Training increases knowledge}

All the participants said that their training had increased their knowledge of the HI virus and helped them cope better with living positively, or helping loved ones close to them to live positively. 'Training was more than good. It gave us knowledge; we learnt to share information and learnt respect for each other.'

\section{Theme 2: Updates are important}

Updates or refresher courses were viewed by all the participants as valuable, and worthwhile. However, the counsellors explained that the opportunity to attend the courses did not occur often, and one participant stated, 'Noone tells us about the updates and everything changes all the time, we need them.' Lehman and Sanders (2007) suggest that refresher courses are just as important as the initial training. If refresher courses are not available, then acquired skills are quickly lost.

Sub theme: The role of the registered nurses and doctors in the clinical area that concerned updating, supervising and teaching the community health workers and lay counsellors. This was discussed by the participants as a sub theme concerning the lack of refresher courses and the need for the participants to update their knowledge. Community health programmes thrive when there is a good relationship with other members of the health team (Campbell and Scott 2009). Relating to this Schneider et al. (2008) found in her study that the professional nurses were positive about the contribution to health care made by the $\mathrm{CHWs}$, but the nurses may respond to the situation by transforming the lay counsellors into nursing assistants (Campbell and Scott 2009). As a
CHW said in her interview; 'they (nurses) have taught me a lot, almost 10 years; I am really like a nurse now. When the sisters are sick I have learnt to run the clinic.' Supervision and support of the CHW is essential in the clinical area, as a result of their brief training, but unfortunately this appears to often be the weakest link in the CHW programmes. The WHO guidelines (WHO 2008:32) on task shifting suggest that extra workers should be hired in a supervisory capacity to provide mentorship and onsite training for the PMTCT CHW.

\section{Theme 3: Role playing teaches you confidence}

The researcher asked the participants about how they were taught, and which mode of delivery they thought best suited their learning. Seven of the participants said that role playing was included in their training and that this was their preferred learning method. Role playing is an ideal way of teaching health education that is built on real life situations (Mellish 1997). Role playing is also a way of creating an environment where different points of view can be discussed in an empathetic way, without the student feeling intimidated and, therefore, allowing her or him to grow in self confidence. The participants also explained that they learnt the most during core lectures, and one participant expressed the opinion that factual knowledge was learnt better in this format 'Classroom is best with a teacher you can ask questions and get answers. 'The researcher suggests that both core lectures and role playing are essential parts of a community health worker's curriculum.

\section{Theme 4: Thoughts about the question, what should be included in a lay counsellors PMTCT community health programme?}

Four subjects emerged from the above question. They included:

- bereavement counselling

- home based care

- tuberculosis knowledge

- nutritional information

Sub theme: Bereavement counselling. The counsellors said that they need to be trained in intergenerational bereavement counselling, 'We are not trained for trauma and bereavement counselling, we are trying, but when parents die and children die it is very stressful.' The researcher explored the role of the social workers in the bereavement counselling process. The community health workers noticed that often their clients were reluctant to consult the social worker as they had built up more of a rapport with them as counsellors, and did not want to involve a new person. 'We try to refer to the social workers for trauma counselling, but the clients feel safe with us, then want to stay.' Community health workers also have to deal with the loss of their community members which, as van Dyk (2009) says, may lead to bereavement overload. This occurs when the counsellor is relentlessly exposed to loss and death without the ability to facilitate debriefing and counselling for themselves. They are, thus, at risk of burnout and leaving their jobs.

Sub theme: Home-based care. Lay counsellors are well known members of their community, and are often involved in 
educating, caring, and supporting community members outside of work. 'The community knows you are a counsellor they ask you for advice.' The participants in this study considered that aspects of home based care should be included in future curricula in order for them to help their community members. 'The mothers are in hospital for one night, we need to know about problems that can happen at home, so we can answer the question.' With the issue of task shifting becoming more embedded in health facilities, community health workers have become more facility orientated and less focused on community health care. There is a need for community health workers to be able to provide their communities with basic health care, which should also include the ability to offer referral advice.

Sub theme: Tuberculosis knowledge. PMTCT lay counsellors, who see mothers on an ongoing basis, are well placed to identify possible co-infections, educate them about tuberculosis drug treatment and its side effects. This would be in line with the WHO's policy of collaboration and co-ordination of TB and HIV activities at all levels (WHO 2008). As a participant stated, 'if people have TB we need to know in order to be able to help them, and tell them about the drug side effects.' The lay counsellors judged that they should have more knowledge about TB to both protect themselves and to offer their communities advice about TB.

Sub theme: Nutritional information. Three of the counsellors considered that nutritional advice should be included in training curricula on a more practical level. Nutrition is not specific to PMTCT support and education but is a community issue, especially in marginalized areas where poverty plays an important part in the patient's nutritional status. In some PMTCT work environments lay counsellors are weighing babies and offering feeding advice. This task includes the well being of the mother if she has chosen to exclusively breast feed. It also provides a platform for nutritional information during the contact with the client. The participants expressed their need for training by explaining that 'General nutritional guidelines are given, but they are not practical. What if a client can't afford health food? Then what? We don't have dieticians here.'

\section{Theme 5: The Government should be responsible for $\mathrm{CHW}$ training}

All the participants agreed that the government should be the provider of CHW and lay counsellors training, and should not be the responsibility of NGO's. Community health workers programmes need careful planning and active government leadership to be successful (Lehman and Sanders 2007). Community health workers have been on the periphery of the health system, and although the state has been the driving force in funding the development of community health workers, they have not been included and integrated in the formal health sector and, therefore, CHWs are not provided with the same employment rights as other government employees. What is important to the lay counsellors is that they have no opportunity for advancement in the health system, and they suspected that this would not change without the involvement of the government. In order for them to progress, the standardization of curricula at their most basic level needs to be addressed, which would provide the lay counsellors with the opportunity to progress into the formal health sector. All categories of CHWs feel vulnerable because of the possibility that if NGOs, who are involved in their training and support, were to leave the country their training would not be transferable, as there is no clear policy at present governing the training and minimum standards expected of CHWs. The base of the health care system is also at risk if health care providers rely on volunteers. This system is not sustainable as CHWs often leave because of their perceived lack of recognition or the lack of potential for them to better themselves in the formal health care sector (IRIN 2009; Schneider et al. 2008).

All the participants were invited to attend a focus group after the semi-structured interviews had been analysed in order to confirm the findings, and alter or add to the findings as deemed necessary in order to accurately record the lay counsellor's thoughts and feelings.

\section{Ethical Considerations}

The following ethical considerations were addressed for this study.

Permission to conduct this research was obtained from the appropriate university faculty on presentation of a written research proposal. Permission was granted from the Medical Committee for Research on Human Subjects, with clearance number M09115. The hospital management of the study site was informed of the study and permission was granted.

\section{Informed consent}

All potential participants were given an information letter outlining the details of the study, prior to scheduling interviews. The researcher obtained a written informed consent form from all the participants. Participants were informed of their right to withdraw from the interview or focus group at any time, with no penalty to themselves.

\section{Data protection}

To ensure anonymity and confidentiality, all field notes tape recordings and interview data were kept under lock and key, and erased immediately after being transcribed. To ensure privacy and confidentiality of the participants, the names of the participants were not mentioned in the final report.

The foreseeable harm, by participating in this study, was not perceived to outweigh the possible benefits for the Community Health Workers. This was discussed with all participants prior to their signing consent.

\section{Trustworthiness}

Lincoln and Guba's four criteria (1985:43) were applied to establish the trustworthiness of this study. 


\section{Credibility}

The researcher proved the credibility of the study by including the following measures:

- Triangulation, which was achieved by the introduction of a focus group, where the participants could add to or alter the data to ensure the accuracy of the findings.

- Member checking, in which the researcher returned to three of the participants with their transcribed interviews and asked them to comment on the content, allowing them to correct any statement that they considered had been misinterpreted by the researcher.

- Authority of the researcher, which asserted that the researcher had completed academic training in research methodology, and was supervised throughout the process by a supervisor with extensive experience and training in research.

\section{Transferability}

To enhance the transferability of the study a thick description was developed of the research methodological framework that was applied in the study.

\section{Dependability}

The detailed description of the data collection and the consistent and documented method of data coding was described, to form part of an audit trail.

\section{Confirmability}

This process includes an explanation of the research process, with a discussion about the sampling method of the participants, from which the data were gathered. Examples of the field notes taken during the study were included in the report. The coding method and themes that were identified are described in detail. All these elements are part of the audit trail that demonstrates the researcher's objectivity and neutrality in the study.

\section{Discussion}

Analysis, of the various curricula for lay counsellors, indicates that the training of community health workers remains more socially orientated than task orientated at present. This is evident in the focus on counselling and listening skills that was present in all three curricula. The results of the semistructured interviews with the lay counsellors indicated that their training had increased their knowledge of HIV and AIDS, but there were areas that they considered had not been adequately covered in their training. These were not nursing tasks but broader in depth counselling skills. The professional nurses in the clinical areas appear to be providing training in tasks that they have delegated to the lay counsellors, as well as providing supervision and mentoring for cadres of community health workers.

Literature that was reviewed for this study suggests that supervision and monitoring of CHWs is a proven weakness in any community programme (Daniels et al. 2010, Lehman and
Sanders 2007) as CHWs are often situated on the periphery of the health care system (Campbell and Scott 2009). This became evident in this study when PMTCT professional nurses were supervisors and mentors. Although there appeared to be provision for refresher courses the CHWs did not appear to attending them.

\section{Limitations of the study}

A limitation to this study was its basis in an academic urban area. The researcher recognises that the lay counsellors working in the field of PMTCT, in the rural areas, may have additional work experiences that they consider should have been included in the PMTCT curriculum. There is a future need to include consultations with a wider range of lay counsellors, CHW and lay educators to ensure that all aspects of counselling education, and the skills thereof, are included in the final curriculum.

A further limitation of the study was the language barrier, the CHWs that took part in this study did not speak English as their first language. All of the interviews were conducted in English, and the researcher, when necessary during the interviews, would ask for clarification if she perceived that the full meaning of the idea may be misunderstood.

\section{Recommendations}

If task shifting is to be an effective answer to the human resources shortage, in providing health care to HIV positive patients, the limitations of training $\mathrm{CHWs}$ must be kept in mind. With attention being given to their future training and education, as well as ongoing support and mentoring, CHWs can become an integral part of the formal health team.

A process of standardization of the $\mathrm{CHW}$ curriculum will allow for accreditation of the training and facilitate further training and personal development of the CHW. This process has begun with providers of HIV and AIDS counselling training applying for accreditation of their unit standards with the South African Quality Assurers.

The problems associated with the lack of formal mentorship and supervision needs to be addressed. A programme in Lusaka, Zambia (Morris et al. 2010) has implemented task shifting that deals with the technical aspects of HIV and AIDS in a didactic class room manner. This is followed by an intensive mentorship in the field where the practical and clinical aspects of education and counselling are addressed. These trained CHWs can then progress to become mentors themselves to a new generation of CHWs.

\section{Conclusion}

In conclusion the training manuals that were reviewed for this study indicate that the curricula vary in content, duration, and teaching style. This is in line with literature that was reviewed for this study (Campbell and Scott 2009; Lehman and Sanders 2007). The problem arises that a lack of defined minimum standards and the quality of the outcomes of the training of CHWs is often inconsistent. 
The CHWs that were interviewed for this study all mentioned that their training had increased their knowledge of HIV and AIDS. The data revealed that the $\mathrm{CHWs}$ would like to have more training on bereavement counselling, home based care, tuberculosis knowledge as well as practical nutritional information. The lack of refresher or update courses, as a component of training, was significant as the CHWs rely on the nurses and doctors for their updates in training, which perpetuates the problem of lack of standardization of CHW training.

The results from this study are documented and are included in a curriculum that can be referred to as part of further research that needs to be undertaken to devise a specific CHW curriculum that specializes in PMTCT.

\section{Acknowledgements}

The author would like to acknowledge all the CHWs who so willingly and openly contributed to this study. Their work load is heavy, with little financial reward, but they remain the foundation of the PMTCT programme in our country, through their education and counselling of the mothers.

To my supervisor Candice Harris who guided and corrected my work giving it focus with patience and diligence.

\section{Competing interest}

The authors declare that they have no financial or personal relationship which may have inappropriately influenced them in writing this artcle.

\section{Authors' contributions}

C.H.T. (University of the Witwatersrand) conducted this study as part of her MSc Nursing, and wrote the manuscript. C.H. (University of the Witwatersrand) was her supervisor throughout the process.

\section{References}

Aids Foundation South Africa, 2009, South Africa's Response to the Epidemic. News Letter, viewed 17 August 2010, from http://www.aids.org.za/hiv/htm.

Bailey, C., 2007, A Guide to Qualitative Field Research, 2nd edn., Pine Forge Press, California.
Beard, C., Wilson, J., 2007, Experiential learning: A best practice handbook for educators and trainers. 2 nd edn., Logan page Limited, United Kingdom.

Bhattacharyya, K., le Ban K. \& Winch, P., Tien M., 2001, 'Community health workers. Incentives and Disincentives. How they affect Motivation, Retention and Sustainability', Basics II, viewed October 2010, from http://www.aed.org/ Publications/upload/CommunityHealthWorkers.pdf.

Campbell, C., Gibbs, A., Maimane S., Nair Y., 2008, 'Hearing community voices: grassroots perceptions of an intervention to support health volunteers in South Africa', Journal of Social Aspects of HIV/AIDS 5(4). $162-177$

Campbell, C., \& Scott K., 2009, Retreat from Alma Ata? The WHO's report on Task Shifting to community health workers for AIDS care in poor countries, Global Public Health, Routledge.

Daniels, K., Nor, B., Jackson D., Ekström E. \& Doherty, T., 2010, Supervision of community peer counsellors for infant feeding in South Africa: an exploratory qualitative study. Human resources for Health, viewed 29 October 2010, from http://www.human-resources-health.com/content/8/1/6.

Health Systems Trust, 2010, Prevention of Mother to Child Transmission Indicators, viewed 17 October 2010, from http://www.hst.org.za/news/20041976.

Henning, E., 2004, Finding your way in qualitative research, Van Schaik Publishers, Pretoria.

IRIN PlusNews, 2009, Kenya: Can lay counsellors fill the health gap? viewed 16 August 2009, from http://www.plusnews.org/Report.aspx?Reportld=85692.

Lehman, U. \& Sanders, D. 2007, Community health workers: what do we know about them? The state of the evidence on programmes, activities, costs and the impact on health outcomes of using community health workers. Geneva department of Human Resources for Development.

Lincoln, Y. \& Guba E., 1985, Naturalistic Inquiry, Sage Publications, California.

Marshall, C. \& Rossman, G., 1995 Designing Qualitative research. 2nd edn., Sage publications, California.

Mellish, J.M., Brink, H. \& Paton, F., 1997, Teaching and learning, the practice of nursing, Heinemann, Johannesburg.

Meyer, S. \& Van Niekerk, S., 2008, Nurse Educator in Practice, Juta, Cape Town.

Morris, M.B., Tambatamba Chapula, B., Chi, B., Mwango, A., Chi H., Mwanza J., 2009, Use of task shifting to rapidly scale-up HIV treatment services: experiences form Lusaka, Zambia, Biomed Central Health Services Research, viewed 28 September 2009, from http://www.biomedcentral.com/content/pdf/1472-6963-9-5.pdf.

Mothers2Mothers, 2006, Annual report, viewed 30 August 2010, from http://www. aidstar-one.com/sites/default/files/g3p_documents/78/M2M-2005_2006 Annual_Report.pdf.

Nieswiadomy, R.M., 2008, Foundation of nursing research, 5th edn., Pearson, Prentice Hall, New Jersey.

Schneider, H., Hlope, H. \& Van Rensburg, D., 2008, Community health workers and the response to HIV/AIDS in South Africa: tensions and prospects. Health policy and Planning Access, published April 3, 2008.

Shenton, K., 2004, 'Strategies for ensuring trustworthiness in Qualitative research', Education for Information 22(2004) 63-75, viewed 20 October 2010, from http:// www.angelfire.com/theforce/shu_cohort_viii/images/Trustworthypaper.pdf.

Van Dyk, A., 2008, HIV/AIDS Care and Counseling A multidisciplinary approach, 4th edn., Pearson Education, South Africa.

USAID, 2009, Aids Epidemic Update/Sub Saharan Africa, viewed 25 October 2010, from http://data.unaids.org/pub/Report/2009/JC1700_Epi_Update_2009_en.pd.

WHO, 2007, Taking Stock: Task shifting to tackle health worker shortages. Health Systems and Services, WHO Press Geneva, viewed October 2010 http://www. who.int/healthsystems/task_shifting_booklet.pdf.

WHO, 2008, Task Shifting: rational redistribution of tasks among health workforce teams: global recommendations and guidelines. WHO Press Geneva, viewed, October 2010 http://www.who.int/healthsystems/TTR-TaskShifting.pdf 